\title{
Mixed-conducting oxygen permeable ceramic membranes for the carbon dioxide reforming of methane $\dagger$
}

\author{
David A. Slade, Andrew M. Duncan, Karen J. Nordheden and Susan M. Stagg-Williams* \\ Received 2nd October 2006, Accepted 2nd January 2007 \\ First published as an Advance Article on the web 1st February 2007 \\ DOI: $10.1039 / b 614232 \mathrm{j}$
}

Due to the high economic, environmental, and safety costs associated with pure oxygen, mixedconducting oxygen-permeable ceramic membranes are being explored as an alternative oxygen source for hydrocarbon conversion reactors. This work reports a dramatic improvement in catalyst performance when an oxygen-permeable $\mathrm{SrFeCo}_{0.5} \mathrm{O}_{x}$ ceramic membrane is used in conjunction with a conventional powder $\mathrm{Pt} / \mathrm{ZrO}_{2}$ catalyst for the $\mathrm{CO}_{2}$ reforming of $\mathrm{CH}_{4}$. Experiments comparing catalyst performance with up to $2 \%$ co-fed oxygen to catalyst performance with oxygen from the ceramic membrane demonstrated a conversion three times higher with the membrane than with any amount of co-fed oxygen. The results suggest that membrane oxygen is more beneficial for catalyst activity and stability than molecular gas-phase oxygen.

\section{Introduction}

With the increasing global demand for cleaner energy, fuel cell hydrogen and ultraclean gas-to-liquid (GTL) fuels are receiving a great deal of attention as alternative energy sources. Mixtures of $\mathrm{H}_{2}$ and $\mathrm{CO}$, known as synthesis gas, serve as the intermediate between hydrocarbon feedstocks and both hydrogen and GTL fuels. Synthesis gas can be produced by reforming reactions (steam, $\mathrm{CO}_{2}$, and autothermal) or partial oxidation reactions, all of which either require or can benefit from pure oxygen as a reactor feed. Among these, partial oxidation of hydrocarbons requires the greatest amount of oxygen and the energy-intensive air separation unit represents a significant fraction of both the operating and capital costs of such a synthesis gas facility. ${ }^{1-4}$

Because of the high economic, environmental, and safety costs associated with pure oxygen, oxygen-permeable ceramic membranes have been explored as an alternative oxygen source for hydrocarbon conversion reactors. ${ }^{1-10}$ These non-porous ceramic materials allow the conduction of oxygen ions through the lattice of the solid material resulting in a $100 \%$ selectivity for oxygen regardless of the source gas. The mixed-conducting materials of interest for membrane reactor applications conduct electrons as well as oxygen ions, so they require only high temperature (typically $700{ }^{\circ} \mathrm{C}$ or higher) and an imposed oxygen potential gradient to transmit oxygen. Unlike solely ionic conducting materials such as those used in solid oxide fuel cells (SOFC's), mixed-conducting ceramics require no external circuitry. Like SOFC ceramics, they exhibit oxygen fluxes that generally increase with temperature above some

Department of Chemical and Petroleum Engineering, University of Kansas, 1530 W. 15th Street, Room 4132 Learned Hall, Lawrence, KS, 66049, USA.E-mail: smwilliams@ku.edu; Fax: +1 785864 4967; Tel: +1 7858644965

$\dagger$ This paper was published as part of the special issue from the "Green Chemistry for Fuel Synthesis and Processing" symposium at the 232nd ACS National Meeting. threshold temperature. A single membrane material was studied in this work: the non-perovskite $\mathrm{SrFeCo}_{0.5} \mathrm{O}_{x}$ mixed oxide referred to henceforth as SFC.

Mixed-conducting ceramics have typically been investigated for use with the partial oxidation of methane (POM) because of its appropriately high operating temperatures and the strongly reducing environment created by the POM reactions. The high reactor temperature allows effective membrane oxygen transport with no additional energy requirement, while the reducing POM environment provides a large oxygen potential gradient even with atmospheric pressure air on the oxygen source side. POM is a desirable commercial reaction because its stoichiometric $\mathrm{H}_{2}$ : $\mathrm{CO}$ ratio of 2 is ideal for Fischer-Tropsch synthesis of liquid hydrocarbons (F-T liquids) and, unlike steam and $\mathrm{CO}_{2}$ reforming, it is an exothermic reaction. These incentives, coupled with the expense of the conventionally-produced oxygen required by POM, have led to its dominance of the membrane reactor field of inquiry.

Although many materials have been identified with measurable oxygen transport ability, only minimal success fabricating membranes that could satisfy the requirements of commercial POM applications has been achieved to date. With these circumstances in mind, it is proposed that lower oxygen fluxes that are currently easy to attain could benefit other reactions that do not require oxygen as a primary reactant yet meet the necessary operating condition requirements of oxygen-permeable ceramic membranes. The high operating temperature and reducing reaction environment of $\mathrm{CO}_{2}$ reforming satisfy these constraints. Furthermore, some studies of oxygen-permeable ceramic membranes have shown that including $\mathrm{CO}_{2}$ on the reaction side or diluting the methane with small amounts of inert gas or oxygen generates a less reducing environment that can prolong membrane lifetime. ${ }^{11,12}$ Thus, membranes that might not be capable of withstanding the severe reducing conditions of the POM reaction could still be acceptable candidates for the $\mathrm{CO}_{2}$ reforming reaction. 
In addition to the possible benefits to catalyst performance, membrane-supplied oxygen incorporates several significant environmental advantages over gas-phase oxygen supplies for synthesis gas operations: (1) the aforementioned substantial reduction in process energy consumption; (2) safer oxygen (no hotspots or flammability concerns); ${ }^{3,8}$ (3) inherently distributed oxygen introduction which can produce a more uniform and predictable reactor temperature profile and increase the selectivity of oxidation reactions; ${ }^{9}$ and (4) minimized occurrence of homogeneous thermochemical reactions involving $\mathrm{O}_{2}$ which can produce soot-forming precursors. ${ }^{13}$ Furthermore, if the resulting synthesis gas is used to produce $\mathrm{F}-\mathrm{T}$ liquids (or oxygenated hydrocarbons via hydroformylation), $\mathrm{CO}_{2}$ reforming itself fits under the green chemistry heading through its utilization of two greenhouse gases as a feedstock.

\section{Experimental}

Reaction and flux tests were performed in the two-sided concentric quartz tube membrane reactor depicted in Fig. 1. The reactor was sealed at high temperatures using gold ring seals between the outer quartz tubes and the membrane surfaces and an external pneumatic press to maintain constant compressive force. The gold seals soften as the reactor system approaches its $800{ }^{\circ} \mathrm{C}$ reaction temperature and the seal is fully formed within $30 \mathrm{~min}$ at $800{ }^{\circ} \mathrm{C}$. In all cases, the leak around the gold rings during operation was estimated as less than $0.2 \%$ of the reactor feed flowrate based on $\mathrm{N}_{2}$ in the reactor effluent. However, it is important to note that leakage during reactor heat-up is unavoidable before the gold seals soften sufficiently near $800{ }^{\circ} \mathrm{C}$. The air content of the effluent during heat-up averages approximately $5 \%$ of the reactor's pretreatment argon feed.

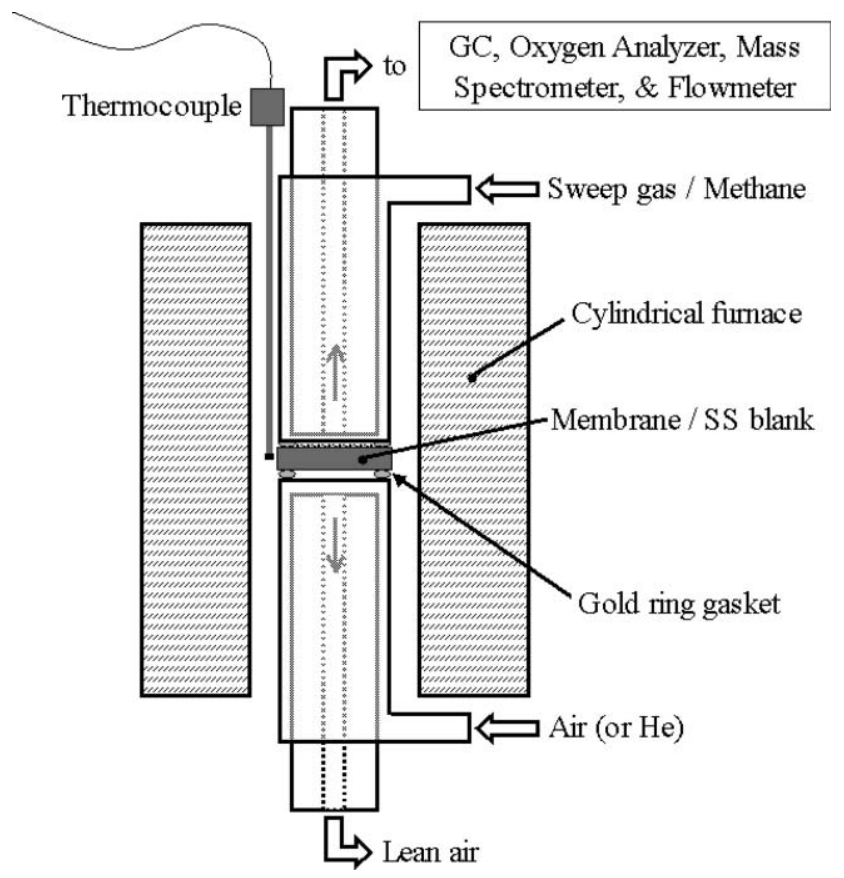

Fig. 1 Schematic of membrane reactor system.
As shown in Fig. 1, reactants flow into the top part of the reactor through the annular space between the two concentric quartz tubes, and effluent leaves the reactor through the inner tube after passing through the catalyst layer on the membrane's top surface. The inner tube has a very thick wall and is positioned as close to the membrane surface as possible (within $1 \mathrm{~mm}$ ) to maximize contact of the gas stream with the catalyst layer.

In addition to the SFC ceramic membranes, a stainless steel "blank" membrane was coated with an inert boron nitride $\left(\mathrm{BN}_{3}\right)$ paint to prevent reaction on the steel surface. This blank membrane was used to examine the effect of co-fed molecular oxygen on catalyst performance and to provide baseline data for the ceramic membrane experiments. The SFC ceramic membranes were pressed at $5000 \mathrm{lb}$ force for $3 \mathrm{~min}$ in a uniaxial press and then sintered at $1180{ }^{\circ} \mathrm{C}$ in flowing air for $10 \mathrm{~h}$. The SFC powder, which was obtained from Praxair Specialty Ceramics, was passed through a 60-mesh sieve and coated with $1 \mathrm{wt} \%$ ethylcellulose binder prior to pressing. The ethylcellulose binder burns off entirely between 350 and $450{ }^{\circ} \mathrm{C}$ and does not affect the density of the finished SFC membranes, which is consistently about $94 \%$ of the theoretical density.

In all reaction tests, the $\mathrm{CH}_{4}: \mathrm{CO}_{2}$ ratio was $1: 1$ and the $\mathrm{CH}_{4}$ and $\mathrm{CO}_{2}$ comprised $80 \%$ of the feed. During the SFC membrane experiments, the remaining $20 \%$ of the feed was pure argon while specific percentages of $\mathrm{O}_{2}$ in Ar were used for experiments with the stainless steel blank membrane. In addition to true $\mathrm{CO}_{2}$ reforming (i.e., no oxygen), the co-fed oxygen amounts tested with the blank were $0.2 \%, 1 \%$, and $2 \%$ $\mathrm{O}_{2}$ of the total volumetric feed flowrate. The feed flowrate corresponded to a space velocity of $150 \mathrm{~L} \mathrm{~h}^{-1} \mathrm{~g}_{\text {cat }}{ }^{-1}$ in all tests. Atmospheric pressure air was used as the oxygen supply at the bottom membrane surface and the SFC membranes were tested for cracks or porosity at the reaction temperature of $800{ }^{\circ} \mathrm{C}$ using slightly pressurized He. No quantifiable $\mathrm{He}$ penetration was detected at $800{ }^{\circ} \mathrm{C}$ before or after reaction.

Catalyst from the same batch of $0.5 \mathrm{wt} \% \mathrm{Pt} / \mathrm{ZrO}_{2}$ catalyst was used in every test. This catalyst was chosen because it has been studied previously in conventional quartz tube PFR reactors ${ }^{14,15}$ and has shown relatively quick deactivation. The catalyst was prepared by depositing $\mathrm{Pt}$ on commercially available $\mathrm{ZrO}_{2}$ support material using the incipient wetness impregnation technique with an aqueous solution of $\mathrm{H}_{2} \mathrm{PtCl}_{6} \cdot 6 \mathrm{H}_{2} \mathrm{O}$. Prior to deposition, the substrate was calcined at $800{ }^{\circ} \mathrm{C}$; after deposition it was dried overnight at $120{ }^{\circ} \mathrm{C}$ and then calcined at $400{ }^{\circ} \mathrm{C}$ for $2 \mathrm{~h}$ in flowing air. BET single point surface area analysis indicated a support surface area of $29 \mathrm{~m}^{2} \mathrm{~g}^{-1}$, and $\mathrm{Pt}$ dispersion was determined to be $21 \%$ by TEM particle size analysis. With two exceptions (described in the "Catalyst pre-treatment effects" section), no catalyst reduction step was performed.

For all membrane reactor experiments, $10 \mathrm{mg}$ of powder $\mathrm{Pt} / \mathrm{ZrO}_{2}$ catalyst was spread in a thin layer $(\sim 1 \mathrm{~mm})$ across the entire portion of the membrane surface (SFC or blank) that was within the reactor's outer quartz tube. This ensured good proximity between the membrane and the entire catalyst bed and minimized transport resistance within the catalyst layer on both the SFC membrane and the blank. Fig. 2 provides a 


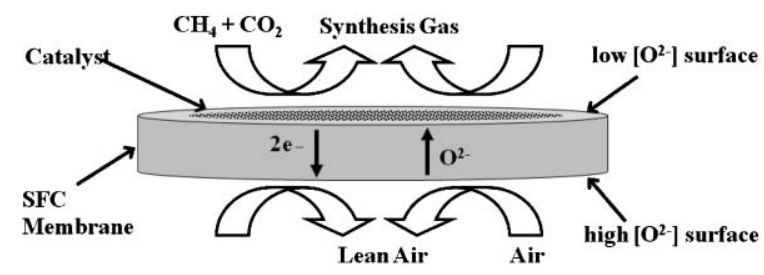

Fig. 2 Schematic of SFC membrane under reaction conditions.

schematic depiction of the SFC membrane under operating conditions.

The reactor was heated to $800{ }^{\circ} \mathrm{C}$ with an argon-only feed and then held at this temperature while the gold seals formed and the membrane equilibrated under the \{air : argon $\}$ oxygen potential gradient. To ensure comparable pre-reaction conditions for the catalyst, this $2 \mathrm{~h}$ hold at $800{ }^{\circ} \mathrm{C}$ was also imposed during all experiments with the stainless steel blank membrane. Steady state oxygen production from the SFC membranes under these conditions was assessed using mass spectrometer data and found to be $0.008 \mathrm{~mL} \mathrm{~min}^{-1} \mathrm{O}_{2}$ for the membranes used in this study. This corresponds to an $\mathrm{O}_{2}$ flux of $0.005 \mathrm{sccm} \mathrm{cm}^{-2}$ at $800{ }^{\circ} \mathrm{C}$.

The reactor effluent composition was quantified using an SRI 8100 gas chromatograph with FID for carbon-containing compounds and TCD for $\mathrm{H}_{2}$ and $\mathrm{N}_{2}$. The effluent was also monitored continuously with a Balzers OmniStar mass spectrometer both to provide important additional information including pre-reaction oxygen flux data and to confirm and interpolate trends observed in the GC data. In addition, effluent flowrate and oxygen concentration were monitored continuously using an Agilent ADM2000 flowmeter and an AMI Model 60 oxygen sensor. Effluent water was calculated from a hydrogen atom balance (trends were confirmed by mass spectrometer results), membrane oxygen flux was calculated from an oxygen atom balance, and carbon deposition was determined from a carbon atom balance.

\section{Results and discussion}

\section{Catalyst pre-treatment effects}

The relatively high oxygen atmosphere experienced by the catalyst during reactor heat-up because of seal leakage undermines the effectiveness of any low temperature catalyst reduction strategy with the membrane reactor. Additionally, catalyst reduction at or near the reaction temperature is not an effective alternative on the SFC membrane because the membrane surface itself reduces readily on exposure to $\mathrm{H}_{2}$ and evolves oxygen in the absence of $\mathrm{H}_{2}$. Because catalyst pretreatment options are limited in the membrane reactor, a conventional quartz tube PFR was used to provide relative catalyst activity data for a selection of catalyst pre-treatment and reactor feed options.

These PFR pre-treatment effect tests were performed for $12 \mathrm{~h}$ at $800{ }^{\circ} \mathrm{C}$ using a catalyst bed that was diluted $40: 1$ by mass with $\mathrm{SiO}_{2}$ powder to minimize thermal effects in the bed. With no co-fed $\mathrm{O}_{2}$, the initial $\mathrm{CH}_{4}$ conversion rate of a reduced catalyst was more than twice the initial rate of the unreduced catalyst. However, as shown in Table 1, this activity
Table 1 Plug flow reactor catalyst pre-treatment test results. Reaction conditions: $T=800{ }^{\circ} \mathrm{C}, 1: 1$ ratio of $\mathrm{CH}_{4}$ and $\mathrm{CO}_{2}$, space velocity of $150 \mathrm{~L} \mathrm{~h}^{-1} \mathrm{~g}_{\text {cat }}{ }^{-1}, 0.5 \mathrm{wt} \% \mathrm{Pt} / \mathrm{ZrO}_{2}$ catalyst, $12 \mathrm{~h}$ time-on-stream

\begin{tabular}{llll}
\hline \multicolumn{2}{l}{ Catalyst pre-treatment } & & Co-fed \\
$\begin{array}{llll}\text { Heating } \\
\text { environment }\end{array}$ & Reduction & & $\begin{array}{l}\text { Final } \mathrm{CH}_{4} \\
\text { oxygen } \\
\mathrm{mmol} \mathrm{min}^{-1} \mathrm{~g}_{\text {cat }}{ }^{-1}\end{array}$ \\
\hline Inert & $\mathrm{H}_{2}$ at $400{ }^{\circ} \mathrm{C}$ & None & 9.0 \\
Inert & None & None & 6.7 \\
Inert & None & $1 \%$ & 8.3 \\
$1 \% \mathrm{O}_{2}$ in $\mathrm{Ar}$ & None & $1 \%$ & 1.9 \\
\hline
\end{tabular}

discrepancy had diminished significantly after $12 \mathrm{~h}$ of $\mathrm{CO}_{2}$ reforming and the reduced catalyst's activity was still declining, approaching the activity of the unreduced catalyst.

Table 1 also presents the baseline effect of co-fed $\mathrm{O}_{2}$ on $\mathrm{CH}_{4}$ conversion using $1 \% \mathrm{O}_{2}$ as a first-pass approximation of the oxygen supplied by an SFC membrane under the applicable reaction conditions. With unreduced catalyst, $\mathrm{CH}_{4}$ conversion increased when co-fed oxygen was included in the reactor feed although the deactivation trends with and without co-fed $\mathrm{O}_{2}$ were parallel. For the final PFR pre-treatment test, the catalyst bed was heated to the reaction temperature in $1 \% \mathrm{O}_{2}$ in $\mathrm{Ar}$ rather than pure Ar to simulate the leak during membrane reactor heat-up, before the gold softened and sealed; $\mathrm{CO}_{2}$ reforming with $1 \%$ co-fed $\mathrm{O}_{2}$ followed. These results confirm that heating in even a small amount of oxygen has a negative effect on the activity of this catalyst. The unreduced catalyst tests all exhibited stable $\mathrm{CH}_{4}$ conversion after 6-7 h of reaction time while the lone reduced catalyst test exhibited declining catalyst activity through the end of the $12 \mathrm{~h}$ experiment. These trends confirm the relevance of the final unreduced catalyst activity data from these tests and also imply that the benefits of a preliminary catalyst reduction step provides only a shortterm benefit with this $\mathrm{Pt} / \mathrm{ZrO}_{2}$ catalyst.

One last investigation on the effect of catalyst pretreatment on its performance in the membrane reactor was performed. Catalyst was pre-reduced in the PFR system before a $10 \mathrm{mg}$ sample was tested in the membrane reactor on the stainless steel blank with $1 \%$ co-fed $\mathrm{O}_{2}$. The pre-reduction step involved heating the catalyst in the PFR to $400{ }^{\circ} \mathrm{C}$ under flowing $\mathrm{H}_{2}$, holding for $1 \mathrm{~h}$, then cooling to room temperature in Ar. The pre-reduction had no effect on the initial or final catalyst activity in the membrane reactor, so no other pre-reaction catalyst reduction steps were performed in this study. However, in situ reduction appears to occur during the onset of $\mathrm{CO}_{2}$ reforming in the membrane reactor to an extent that depends on the amount of co-fed $\mathrm{O}_{2}$.

\section{Membrane reactor results}

In the membrane reactor with the stainless steel blank membrane the first-pass estimate of $1 \%$ co-fed $\mathrm{O}_{2}$ exhibited a similar relationship to the no oxygen case as in the PFR tests. The initial $\mathrm{CH}_{4}$ conversion was higher with $1 \% \mathrm{O}_{2}$ than without $\mathrm{O}_{2}$, but the deactivation trend was the same in both cases and minimal changes in conversion were observed after $7 \mathrm{~h}$ of reaction. As shown in Fig. 3, a dramatic difference in both rate and extent of deactivation was observed with the same catalyst loading on the SFC membrane, and these results 


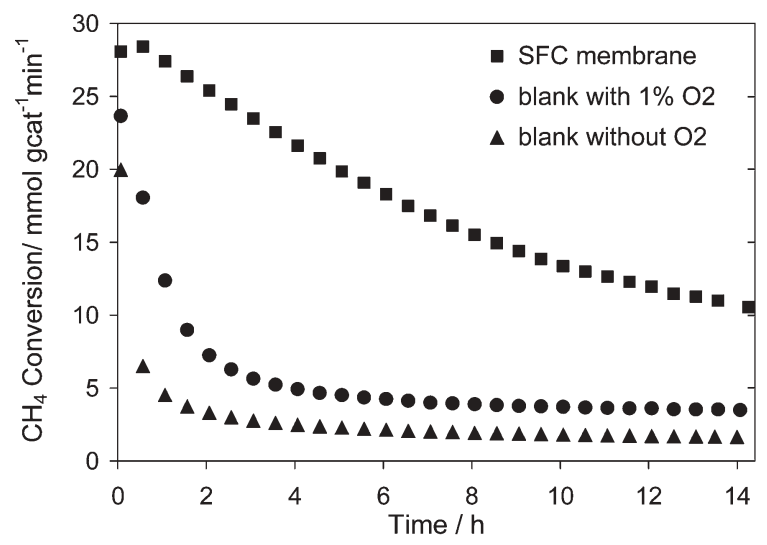

Fig. 3 Membrane reactor test results for the SFC membrane and the stainless steel blank (with and without co-fed $\mathrm{O}_{2}$ ). Reaction conditions: $T=800{ }^{\circ} \mathrm{C}, 1: 1$ ratio of $\mathrm{CH}_{4}$ and $\mathrm{CO}_{2}$, and a space velocity of $150 \mathrm{~L} \mathrm{~h}^{-1} \mathrm{~g}_{\text {cat }}{ }^{-1}$ with $0.5 \mathrm{wt} \% \mathrm{Pt} / \mathrm{ZrO}_{2}$ catalyst.

imply that oxygen supplied via a ceramic membrane both enhances and preserves the activity of the $\mathrm{Pt} / \mathrm{ZrO}_{2}$ catalyst. Similar catalyst preservation results have been reported for a $\mathrm{Ni} / \gamma-\mathrm{Al}_{2} \mathrm{O}_{3}$ catalyst in a $\mathrm{POM}$ membrane reactor system. ${ }^{4}$

Other co-fed $\mathrm{O}_{2}$ levels of interest were identified from estimates of membrane oxygen production during the reaction depicted in Fig. 3. These oxygen production values were calculated from GC data and indicate that membrane oxygen production stabilized at a value of $\sim 0.02 \mathrm{~mL} \mathrm{~min}^{-1}$ (gasphase $\mathrm{O}_{2}$ equivalent) after $6 \mathrm{~h}$ of exposure to the reaction conditions. This amount of $\mathrm{O}_{2}$ would represent $0.08 \%$ of the feed if it were co-fed, and it is also 2.5 times the steady state oxygen production observed prior to reaction under the \{air : argon $\}$ oxygen potential gradient. Table 2 provides four additional membrane oxygen production estimates at times spanning the reaction period, with the second row presenting the equivalent feed percentage if the membrane oxygen had been co-fed in the gas phase and the third row displaying the multiple of the pre-reaction membrane oxygen production represented by the oxygen produced under reaction conditions.

The first two values in the third row of Table 2 do not represent true oxygen flux through the membrane but rather a "dumping" of oxygen from the membrane as it equilibrates with its new environment. Because the environment over the top surface of the membrane is changed from argon to a much more reducing syngas-containing environment, membrane oxygen production is initially high. It then drops quickly as the membrane begins to equilibrate with the reaction environment. Since the amount of oxygen produced by the membrane was not constant throughout the test period, two additional levels of co-fed $\mathrm{O}_{2}$ were selected to test with the stainless steel blank: $2 \%$ co-fed $\mathrm{O}_{2}$ to reproduce the high initial oxygen production and $0.2 \%$ to represent the low steady state production.

Table 2 Membrane oxygen production estimates during reaction

\begin{tabular}{lllll}
\hline Time on stream/h & 0 & 2 & 7 & 14 \\
Equivalent co-fed $\mathrm{O}_{2}(\%)$ & 2.0 & 0.47 & 0.07 & 0.06 \\
Multiple of $\{$ air : argon\} flux & 64 & 15 & 2.1 & 1.9 \\
\hline
\end{tabular}

Table 3 Membrane reactor test results for all tests. $\mathrm{CH}_{4}$ conversion units $=\mathrm{mmol} \mathrm{min}^{-1} \mathrm{~g}_{\text {cat }}{ }^{-1}$. Reaction conditions: $T=800^{\circ} \mathrm{C}, 1: 1$ ratio of $\mathrm{CH}_{4}$ and $\mathrm{CO}_{2}$, and a space velocity of $150 \mathrm{~L} \mathrm{~h}^{-1} \mathrm{~g}_{\text {cat }}{ }^{-1}$ with $0.5 \mathrm{wt} \%$ $\mathrm{Pt} / \mathrm{ZrO}_{2}$ catalyst

\begin{tabular}{llc}
\hline $\begin{array}{l}\text { Oxygen } \\
\text { addition }\end{array}$ & $\begin{array}{l}\text { Initial } \mathrm{CH}_{4} \\
\text { conversion }\end{array}$ & $\begin{array}{l}\mathrm{CH}_{4} \text { conversion } \\
\text { after } 14 \mathrm{~h}\end{array}$ \\
\hline Membrane & 28.0 & 10.3 \\
$2 \%$ Co-fed & 13.4 & 2.6 \\
$1 \%$ Co-fed & 23.5 & 3.4 \\
$0.2 \%$ & 25.4 & 2.9 \\
None & 19.8 & 1.6 \\
\hline
\end{tabular}

These final two tests were performed to determine whether catalyst activity enhancement or preservation effects could be achieved with co-fed oxygen. However, they exhibited the same deactivation trend as the previous tests using the stainless steel blank. Table 3 presents the initial and final $\mathrm{CH}_{4}$ conversion values for all of the membrane reactor tests described in this work. Although the $0.2 \%$ co-fed $\mathrm{O}_{2}$ experiment showed an initially higher $\mathrm{CH}_{4}$ conversion than the $1 \% \mathrm{O}_{2}$ test, this was the only point at which its activity exceeded that of the $1 \%$ $\mathrm{O}_{2}$ case. Surprisingly, the $2 \% \mathrm{O}_{2}$ test showed the lowest initial activity of any of the tests, which removed the possibility that an initial release of gas-phase oxygen from the SFC material was responsible for the high catalyst activity with the SFC membrane. By the second $\mathrm{GC}$ injection (i.e., $35 \mathrm{~min}$ of reaction time) $\mathrm{CH}_{4}$ conversion with $2 \%$ co-fed $\mathrm{O}_{2}$ had exceeded that of the no oxygen case, but it remained significantly below the lower co-fed $\mathrm{O}_{2}$ cases throughout the test period. These observations are consistent with the possibility that in situ catalyst reduction can be hampered by co-fed $\mathrm{O}_{2}$.

The results of this study suggest that membrane oxygen is more reactive than co-fed molecular oxygen. It should be noted that $\mathrm{CH}_{4}$ conversion on the membrane without catalyst was less than $1 \%$ at all times. Thus, the combination of catalyst and SFC membrane is needed to produce the observed benefit from membrane oxygen; the SFC surface alone has minimal activity with the $\mathrm{CO}_{2}$ reforming feed gases. The stainless steel blank without catalyst also produced conversions less than $1 \%$, confirming that gas-phase reactions are negligible under these operating conditions.

While the exact role of oxygen in the reaction mechanism has not yet been determined, several possibilities are being explored. The first is that oxygen ions recombine to form molecular oxygen after they diffuse through the membrane material and then desorb from the membrane surface before reacting. This molecular oxygen would be introduced at the bottom of the catalyst bed and would thus compete less with $\mathrm{CH}_{4}$ for active $\mathrm{Pt}$ sites than in the co-fed $\mathrm{O}_{2}$ cases. Although this scenario is consistent with the increased activity with the ceramic membrane, it is unlikely that oxygen ions on the surface of the membrane would preferentially recombine to form molecular oxygen and desorb from the surface before reacting with the readily available hydrogen in the highly reducing reaction environment.

An alternate explanation is that the oxygen ions on the surface of the membrane react directly with hydrogen produced by methane decomposition. Membrane oxygen is not expected to react directly with $\mathrm{CH}_{4}$ in significant quantities 
since, as previously stated, $\mathrm{CH}_{4}$ conversion in the absence of catalyst is negligible. However, water produced by the oxidation of hydrogen at the membrane surface could increase $\mathrm{CH}_{4}$ conversion by participating in steam reforming as it passes out through the catalyst layer.

The final explanation is that oxygen could migrate from the membrane surface to the catalyst via the oxygen ion conducting $\mathrm{ZrO}_{2}$ support. The oxygen species on the catalyst could then participate in the reactions. While these results do not differentiate between oxygen species spillover onto the $\mathrm{Pt} / \mathrm{ZrO}_{2}$ catalyst or oxygen species reacting on the membrane surface, they do confirm that SFC alone does not activate methane and demonstrate that the catalyst and the membrane work in concert to achieve the observed improvement.

\section{Conclusions}

Dense ceramic $\mathrm{SrFeCo}_{0.5} \mathrm{O}_{x}$ membranes have been investigated as a means of adding small amounts of distributed oxygen to the $\mathrm{CO}_{2}$ reforming of $\mathrm{CH}_{4}$ reaction in a planar membrane reactor. These membrane reactor experiments revealed two distinct phenomena. The first phenomenon, the effect of small amounts of co-fed $\mathrm{O}_{2}$ on unreduced catalyst activity, should apply to any conventional catalytic reactor system. As observed from the set of four co-fed $\mathrm{O}_{2}$ levels with the stainless steel blank (including the no oxygen case), the effect of gas-phase oxygen on the activity of the unreduced $\mathrm{Pt} / \mathrm{ZrO}_{2}$ catalyst depends on the amount of oxygen supplied. As expected, co-fed $\mathrm{O}_{2}$ increases $\mathrm{CH}_{4}$ conversion over the no oxygen scenario, but above some optimum concentration it also appears to hinder in situ reduction and thereby reduce catalyst performance. For this $\mathrm{Pt} / \mathrm{ZrO}_{2}$ catalyst in the unreduced condition, the optimal co-fed oxygen amount falls somewhere between 0.2 and $1 \%$.

The second phenomenon is the dramatic effect of the SFC membrane on the $\mathrm{Pt} / \mathrm{ZrO}_{2}$ catalyst's activity. While this effect requires further study to elucidate the specific role of membrane oxygen, the results presented herein indicate the substantial promise of this novel application for oxygenpermeable ceramic membranes. The combination of the enhanced catalyst performance with the significant environmental advantages of membrane oxygen encourages further exploration of ceramic membrane reactors for $\mathrm{CO}_{2}$ reforming.

\section{Acknowledgements}

Financial support for this project was provided by the Office of Naval Research (N00014-03-1-0601).

\section{References}

1 U. Balachandran, J. T. Dusek, P. S. Maiya, B. Ma, R. L. Mieville, M. S. Kleefisch and C. A. Udovich, Catal. Today, 1997, 36, 265.

2 P. N. Dyer, R. E. Richards, S. L. Russek and D. M. Taylor, Solid State Ionics, 2000, 134, 21.

3 H. J. Bouwmeester, Catal. Today, 2003, 82, 141.

4 S. J. Feng, S. Ran, D. C. Zhu, W. Liu and C. S. Chen, Energy Fuels, 2004, 18, 385.

5 P. S. Maiya, U. Balachandran, J. T. Dusek, R. L. Mieville, M. S. Kleefisch and C. A. Udovich, Solid State Ionics, 1997, 99, 1.

6 E. T. Robinson, S. Aasland and J. Chen, Proceedings of the 2004 AIChE Spring Meeting, New Orleans, Louisiana, 2004, paper \#68d.

7 A. F. Sammells, M. Schwartz, R. A. Mackay, T. F. Barton and D. R. Peterson, Catal. Today, 2000, 56, 325.

8 J. Tong, W. Yang, R. Cai, B. Zhu and L. C. L. Lin, Catal. Lett., 2002, 78(1-4), 129.

9 J. T. Ritchie, J. T. Richardson and D. Luss, AIChE J., 2001, 47(9), 2092.

10 C.-Y. Tsai, A. G. Dixon, Y. H. Ma, W. R. Moser and M. R. Pascucci, J. Am. Ceram. Soc., 1998, 81(6), 1437.

11 C.-Y. Tsai, A. G. Dixon, W. R. Moser and Y. H. Ma, AIChE J., 1997, 43(11A), 2741.

$12 \mathrm{X}$. Gu, L. Yang, W. Jin, L. Zhang and N. Xu, Ind. Eng. Chem. Res., 2003, 42, 795.

13 J. J. Spivey, Proceedings of the 232nd American Chemical Society National Meeting, San Francisco, California, September 2006, paper \#136.

14 W. Wang, S. M. Stagg-Williams, F. B. Noronha, L. V. Mattos and F. B. Passos, Catal. Today, 2004, 98, 553-563.

15 J. H. Bitter, K. Seshan and J. A. Lercher, J. Catal., 1997, 171, 279-286. 